\title{
Students' Motivation to Learn English as a Foreign Language in the Context of Saudi Arabian Learners
}

\author{
Hind Aljuaid \\ Department of Foreign Languages, College of Arts \\ Taif University, Taif, Saudi Arabia \\ Email:dr.hind@tu.edu.sa
}

Received: 4/16/2021

Accepted: 8/30/2021

Published: 9/24/2021

\begin{abstract}
Motivation is the major contributor to the students' learning English as a second language. However, varying reasons have been suggested by different researchers and theorists to explain the reasons and dimensions of this motivation. Therefore, the study aimed to evaluate the motivation to learn English as a foreign language (EFL) among 157 Saudi Arabian university students. The instrument used for the analysis was a modified version of the motivation scale developed by Wen (1997), which measures motivation based on six subscales: integrative, instrumental, effort, valence, expectation, and ability. In addition, students' motivation was compared among students with different English language levels using multivariate analysis of variance (MANOVA) on six motivation subscales. The results of the MANOVA revealed that there was no significant difference among students of different levels of English knowledge when each level was compared separately. Nevertheless, when comparing a merged group of students with English level knowledge of $1^{\text {st }}$ to $3^{\text {rd }}$ with the group of $4^{\text {th }}$ level, the motivation of the latter group was statistically significantly higher. Furthermore, the difference in mean values was significant for integrative, effort, valence, and ability subscales. Thus, the findings of this research depicted that instrumental and integrative motivations could be the main contributor to students' motivation to learn English as a foreign language.
\end{abstract}

Keywords: English as a foreign language (EFL), instrumental motivation, integrative motivation, language learning, motivation, second language

Cite as: Aljuaid, H. (2021). Students' Motivation to Learn English as a Foreign Language in the Context of Saudi Arabian Learners . Arab World English Journal, 12 (3) 242-256.

DOI: https://dx.doi.org/10.24093/awej/vol12no3.17 


\section{Introduction}

It is unclear what part motivation plays in a learner acquiring a second language. Second Language Acquisition (SLA) theorists see motivation as an element that only affects other factors that come into play when developing a second language. However, it is safe to say that their view of motivation is limited; students have a great desire to be more in control of their learning process. They long to know what direction will help them advance further in their language acquisition. A learner's efforts and decisions are the main contributors to acquiring a second language. They are who decide which books they are going to read, which courses they are going to pursue, etc., and motivation has a huge role in that.

Research into what role motivation plays in SLA has shown two types of motivation: integrative and instrumental (Gardner \& Lambert, 1959). Integrative motivation is the type of motivation that makes a learner try to acquire some of the cultural aspects of the people who speak the language they are trying to develop natively. On the other hand, instrumental motivation empowers a learner to learn a second language by aiming to attain a certain goalgetting employed. Therefore, Gardner and Lambert proposed that in addition to learning a second language, learners must take on the integrative approach whereby they try to recognize how cultural beliefs play a part in developing the language they are trying to take on. Therefore, both the integrative and instrumental being incorporated by a learner further boosts his acquisition of a second language.

However, other studies have mixed outcomes regarding Gardner's motivation models of acquiring a second language. Some researchers, such as Oller Jr (1981) and Au (1988), have shown that integrative motivation is not superior to the instrumental motivation approach. Some studies indicate that instrumental motivation is even more critical when acquiring English as a foreign language (EFL) than integrative motivation. Therefore, many researchers conclude that motivation, especially the model proposed by Gardner, is inconsistent depending on the learner, context, and tasks to be accomplished in the learning process.

Other models have proposed that learning English as a foreign language entails three components.

- Language level - entails the instrumental and integrative categories

- Learner level - contains the learners desire to achieve more and their confidence

- Learning-situation level - comprises the course contents, teachers, and groups with which a learner is involved.

In particular, this research aimed to answer the following questions:

1. To what extent are the determinants of learners' motivation to acquire a foreign language (integrative motivation, instrumental motivation, effort, valence, expectancy, ability) internally related?

2. Is there a difference among students with different proficiency levels in their motivation to learn EFL?

The first question seeks to understand how an individual's characteristics influence the toll that the motivation takes on the individual to influence the learner's acquisition of a foreign language. The second question seeks to assess if there is a varying degree of motivation between 
a person who is a proficient learner of English and a person who is not all that good. Some studies have shown a slight relationship between integrative motivation and greater proficiency in foreign languages. However, it is still unclear if these findings can be applied to university students taking on English as a foreign language.

The study proposed the following hypothesis in light of the discussions concerning the part motivation plays in the acquisition of a foreign language:

- An individual's level of motivation and their proficiency in a foreign language does not portray much disparity,

- Merged groups of students taking on EFL showcase no difference in their level of motivation depending on their level of proficiency

- The integrative motivation approach to acquiring a foreign language is more superior to the instrumental motivation approach.

\section{Literature Review}

A growing set of peer-reviewed literature has evidenced the increasing trends of English learning as a second language among university students at various levels. Furthermore, it has depicted multiple factors responsible for this ever-growing motivation.

Anjomshoa and Sadighi (2015) argued that motivation is essential for learning English as a foreign language (EFL). They opined that intrinsic and extrinsic motivation contributes to students' learning attitude towards English as a foreign language.

Nawaz, Amin, and Tatla (2015) investigated the factors that influenced students' motivation to learn English as a second language among 400 respondents. They employed a mix of qualitative and quantitative approaches. They found that integrity, international exposure, English anxiety, interest, and travel orientation contributed to the students' motivation to develop English as their second language. Claro (2016) also found that integrativeness is one of the primary indicators behind engineering students' learning attitude towards the English language. Batubara, Derin, Putri, and Yudar (2020) also performed a study and identified five crucial factors that influence students' motivation towards English learning as a second language. They reported these five factors, including the presence of teachers, personal learning attitude, Montessori materials, classroom environment, and friends' influence.

In another study conducted by Pham (2016), a particular emphasis was placed on sociocultural factors contributing to the students' motivation to adopt English as a second language in high schools. Based on their findings, they pointed out that encouragement from parents, nearpeer effect and the perceived value of English for the achievement of their personal goals played a pivotal role in students' motivation to learn English as their second language along with their primary language.

Suryasa, Prayoga, and Werdistira (2017) conducted a study to evaluate the students' motivation to learn English as a second language among 30 respondents. The questionnaire was derived from the Attitude/Motivation Test Battery (AMTB) design. The results depicted that students were primarily motivated towards English learning as a second language due to 
instrumental motivation. They concluded that from such an analysis, valuable strategies to improve students' motivation could be devised.

Ngo, Spooner-Lane, and Mergler (2017) investigated a study to evaluate the motivation for English learning as a second language among English majoring and non-English majoring students. For this purpose, they employed a quantitative design to assess various types of motivation. They found that both great groups had high motivation for English learning as they needed it to prepare for future professions. Moreover, those students who had intrinsic motivation invested the most increased effort to learn English.

Jin (2014) also executed a study to assess integrative and instrumental motivation among non-English majoring students. They found that students often have an expectation and develop strong integrative motivation, leading them to English learning as a second language. Teachers' motivation also plays an integral part in this regard. The study conducted by Vibulphol (2016) also revealed the role of teachers' motivational strategies in enhancing students learning attitudes towards English as a second language. They also found that these motivational strategies increased students' intrinsic motivation for English learning both inside and outside the classroom. Rahman et al. (2017) also argued that teachers' attitudes and motivational influences impacted the students' motivation to learn English as a foreign language.

Batubara et al. (2020) conducted a gender-based study to evaluate students; motivation to learn English as a foreign language. They found that various factors influenced English learning motivation in the classroom, including empowerment, usefulness, success, interest, and caring. They pointed out that female learners experienced low levels of these factors as compared to male counterparts. They concluded that teachers need to create a learning environment where all students can share these factors associated with motivation, especially females and other low achievers.

\section{Methodology \\ Population}

A total of one hundred and fifty-seven students $(n=157)$ participated in the study. The students majoring in English Language and Literature at Taif University, a state university in Saudi Arabia, are treated as the population in this research. The English Language and Literature Programme, where the participants were enrolled, consists of four years of formal study at the university. Students must complete courses to boost their English language skills (reading, writing, listening, and speaking) in the first two years. In the last two years, students must take courses related to literature and linguistics to cultivate their literary appreciation and criticalanalytical ability and deepen their knowledge of the various branches of modern linguistic theory.

\section{Research Instrument}

A modified version of the Wen (1997) scale has been used for data collection, consisting of 40 items divided into three parts. Part one included demographic questions (6 items) about the participants' age, gender, level of English. Part two consisted of three subscales (16 items) measuring the factors of integrative motivation, instrumental motivation, and effort. Finally, part 3 consisted of three subscales (18 items) measuring valence, expectancy, and ability factors. 


\section{Data Analysis}

This study employed Gardner and Lambert's (1959) integrative and instrumental concepts and an expectancy theory proposed by Wen (1997). Wen's theory suggests four motivational factors empower learners to learn a new language and stick with it. These are instrumentality, learning strategies and efforts expected to be undertaken by the student, intrinsic motivation, and abiding by the requirements. Expectancy refers to the possibility of being successful when undertaking a specific task.

The questionnaires filled by 157 English students were input and then analyzed using IBM SPSS software. It was double-checked after input and then checked by comparing minimum and maximum values for each variable with possible values according to the instrument used to ensure data input accuracy.

The mean values for each set of questions were calculated to create six composite scores for motivation subscales. The mean values were chosen instead of summing the answers for each scale as done in previous research (Shaaban \& Ghaith, 2000). This is because they are more evident for interpretation as their minimum and maximum value fit the range of Likert scales used in separate questions building the scale (Table 1).

Table 1

Motivation scales description

\begin{tabular}{|c|c|c|c|c|c|}
\hline Scale name & Items & & Measurement & Range & $\begin{array}{l}\text { Cronbach's } \\
\text { alpha }\end{array}$ \\
\hline Integrative & $\begin{array}{l}\text { Motivation information } \\
\text { Questions } 1,2,3,4,6\end{array}$ & section. & 7-point Likert scale & 1 to 7 & .800 \\
\hline Instrumental & $\begin{array}{l}\text { Motivation information } \\
\text { Questions 5,7,8,9,10 }\end{array}$ & section. & 7-point Likert scale & 1 to 7 & .833 \\
\hline Effort & $\begin{array}{l}\text { Motivation information } \\
\text { Questions 11,12, 13, 14, 15, } 16\end{array}$ & section. & 4-point ordinal scale & 1 to 4 & .632 \\
\hline Valence & $\begin{array}{l}\text { Information on learning } \\
\text { section; Valence. } \\
\text { Questions } 1,2,3,4,5,6\end{array}$ & utcomes & 7-point Likert scale & 1 to 7 & .873 \\
\hline Expectancy & $\begin{array}{l}\text { Information on learning } \\
\text { section; Expectancy. } \\
\text { Questions } 1,2,3,4,5,6\end{array}$ & utcomes & 11 point Likert scale & 0 to 100 & .877 \\
\hline Ability & $\begin{array}{l}\text { Information on learning } \\
\text { section; Ability. } \\
\text { Questions } 1,2,3,4,5,6\end{array}$ & putcomes & 11 point Likert scale & 0 to 100 & .890 \\
\hline
\end{tabular}

The next issue in the data was several missing answers for some of the scales. For example, some of the respondents missed 1 to 2 answers in some of the scales. However, as these missing answers were not regular but occurred only in single questions, the mean values were still calculated. The main reason for this decision was the number of interviews included in further MANOVA after removing all cases with at least one missing answer in 34 motivation questions. As a result, all cases that did not get information about students' English level decreased by almost a third and reached only 109 respondents.

Moreover, among these 109 respondents, only 6 had second English level, which was the lower border for MANOVA, applied for six subscales. Thus, the cases with single missing 
answers on the motivation questions were included in the analysis. All 135 respondents who provided their level and did not miss any whole block of questions for the motivation subscale were included in the analysis.

The internal consistency of the motivation subscales was checked by calculating Cronbach's alpha (Table 1). The results (all $\alpha>0.8$ except effort subscale with $\alpha=0.632$ ) proved the high internal consistency of each subscale, which confirmed they were a reliable instrument to measure motivation to learn English.

A total score was calculated to receive an overall estimation of students' motivation to learn English. Considering that the motivation subscales were measured based on different Likert scales and therefore had different ranges, their values were first normalized to fit 0 to 1 . Then six normalized scores for subscales summed up for each respondent resulted in a total motivation score with a theoretically possible range from a minimum value of 0 and a maximum value of 6 .

Descriptive statistics were calculated for all motivation subscales, and the correlation analysis was applied to investigate the relationship between each pair of motivation subscales and the total motivation score. Pearson's correlation coefficients calculated for all subscales and total score provided information about the sign and strength of the relationship.

To compare the students' motivation with different levels of English, a multivariate analysis of variance (MANOVA) was performed using six motivation subscales as the dependent variable and English knowledge level as the independent variable. Before conducting MANOVA, the dependent variables were tested to correspond to the primary assumption of the analysis (Hair, Black, Babin, Anderson, \& Tatham, 2006):

- There should not be any univariate and multivariate outliers in the dependent variables. The first can be checked by using a boxplot for each dependent variable within each independent variable group. The Mahalanobis distance can be observed and compared to the Chi-square distribution with degrees of freedom equal to the number of dependent variables to check for multivariate outliers.

- The dependent variables should be normally distributed for every level of the independent variable. This was tested using the Shapiro-Wilk test for normality.

- The dependent variables should have a significant but not too high correlation.

- The variance of dependent variables should be equal between the independent variable groups, which was tested using Leven's homogeneity of variance test.

- There should be homogeneity of variance-covariance matrices, which can be investigated by analyzing the results of Box's $M$ test of equality of covariance.

Along with multivariate tests, univariate inferential statistics (ANOVA) evaluated the subscales between students with different English language levels. Wilks' Lambda values were used, followed by F-test values for ANOVA to test the statistical significance for MANOVA. The corresponding $\mathrm{p}$-values of the test statistics were compared to the conventional significance level $\alpha=.05$. The null hypothesis of equality of values was rejected if $p<.05$ 


\section{Results}

One hundred fifty-seven respondents participated in the study and provided their answers. However, a perceptible share of them missed the first part of the questionnaire about their sociodemographic characteristics. Thus participants' descriptive statistic was obtained for only 135 respondents (Table 2). Furthermore, although almost all of the respondents were females $(\mathrm{n}=$ $131,97.0 \%)$, the age of the participants who shared this data $(\mathrm{n}=111)$ ranged from 18 to 38 years old with a mean age of $21.7(\mathrm{SD}=2.2)$ and a median of 22 years old.

Over half of the participants were in their fourth year of English learning $(n=72,52.9 \%)$. The groups of first- and third-year students were almost equal, around a fifth of the sample $(\mathrm{n}=$ $28,20.6 \%$ and $n=25,18.2 \%$ ), and the share of those who were in their second year was the lowest with only 11 participants $(8.1 \%)$.

The share of those who provided information about their major was relatively low $(\mathrm{n}=$ 43, 27.4\%), and the most frequent answers among these respondents were English $(\mathrm{n}=24$, $55.8 \%)$ and English literature $(\mathrm{n}=13,30.2 \%)$. All respondents except one mentioned Arabic as their first language and English as their first foreign language.

Table 2

Participants' descriptive statistics

\begin{tabular}{llll}
\hline \multirow{3}{*}{ Gender } & & $\mathrm{n}$ & $\%$ \\
& Male & 4 & $3.0 \%$ \\
& Female & 131 & $97.0 \%$ \\
& $<22$ y.o. & 53 & $47.7 \%$ \\
& $\geq 22$ y.o. & 58 & $52.3 \%$ \\
\multirow{4}{*}{ Level } & 1 & 28 & $20.6 \%$ \\
& 2 & 11 & $8.1 \%$ \\
& 3 & 25 & $18.4 \%$ \\
\multirow{6}{*}{ Major } & 4 & 72 & $52.9 \%$ \\
& English & 24 & $55.8 \%$ \\
& English literature & 13 & $30.2 \%$ \\
& Other & 6 & $14.0 \%$ \\
\hline
\end{tabular}

The mean scores of motivation subscales and their standard deviations compared between different English levels are presented in Table 3. According to the results, the mean scores are higher than possible scale midpoints for all motivation subscales. However, there was no noticeable trend in changing motivational subscales and total scale scores; thus, only further MANOVA analysis could answer whether there was a significant difference in the students' motivation with different English levels.

Table 3

Descriptive Statistics for motivation subscales by level of English

\begin{tabular}{lllllllllll}
\hline Variable & $\begin{array}{l}\text { Total } \\
\mathrm{M}\end{array}$ & $\mathrm{SD}$ & $\begin{array}{l}\text { Level 1 } \\
\mathrm{M}\end{array}$ & $\mathrm{SD}$ & $\begin{array}{l}\text { Level 2 } \\
\mathrm{M}\end{array}$ & $\mathrm{SD}$ & $\begin{array}{l}\text { Level 3 } \\
\mathrm{M}\end{array}$ & $\mathrm{SD}$ & $\mathrm{M}$ & $\mathrm{SD}$ \\
\hline $\begin{array}{l}\text { Integrative } \\
(1-7)\end{array}$ & 5.03 & 1.30 & 4.91 & 1.37 & 4.47 & 1.22 & 4.94 & 1.24 & 5.35 & 1.26 \\
\hline
\end{tabular}


Arab World English Journal (AWEJ) Volume 12. Number 3. September 2021

Students' Motivation to Learn English as a Foreign Language

Aljuaid

\begin{tabular}{lcccccccccc}
\hline $\begin{array}{l}\text { Instrumental } \\
(1-7)\end{array}$ & 5.35 & 1.44 & 5.36 & 1.33 & 4.93 & 1.69 & 5.53 & 1.58 & 5.38 & 1.50 \\
$\begin{array}{l}\text { Effort } \\
(1-4)\end{array}$ & 2.76 & 0.59 & 2.73 & 0.58 & 2.63 & 0.45 & 2.67 & 0.67 & 2.89 & 0.55 \\
$\begin{array}{l}\text { Valence } \\
(1-7)\end{array}$ & 5.04 & 1.39 & 4.67 & 1.24 & 4.78 & 1.33 & 5.02 & 1.41 & 5.29 & 1.49 \\
$\begin{array}{l}\text { Expectancy } \\
(0-100)\end{array}$ & 63.10 & 18.45 & 61.52 & 16.85 & 63.33 & 15.55 & 60.15 & 19.91 & 65.67 & 18.31 \\
$\begin{array}{l}\text { Ability } \\
(0-100)\end{array}$ & 64.25 & 19.91 & 59.75 & 21.22 & 57.12 & 19.18 & 62.20 & 20.37 & 69.46 & 18.20 \\
$\begin{array}{l}\text { Total } \\
(0-6)\end{array}$ & 3.94 & 1.00 & 3.78 & 1.00 & 3.61 & 0.93 & 3.86 & 1.04 & 4.17 & 0.99 \\
\hline
\end{tabular}

As the motivation subscales were measured based on different Likert scales, they were normalized to the 0-1 range to get the ability to compare motivation aspects with each other (Figure 1). The results showed that among research participants instrumental motivation is the highest $(\mathrm{M}=0.73, \mathrm{SD}=0.25)$ followed by integrative motivation $(\mathrm{M}=0.68, \mathrm{SD}=0.22)$ and valence $(\mathrm{M}=0.68, \mathrm{SD}=0.24)$. Then comes the pair of motivation aspects: students' expectancy and ability levels $(\mathrm{M}=0.64, \mathrm{SD}=0.18$ and $\mathrm{M}=0.65, \mathrm{SD}=0.20$ correspondingly). The lowest motivation among respondents was measured for their effort $(M=0.60, S D=0.19)$. A pairedsamples t-test was performed for each pair of motivation subscales to check the difference in mean values. According to the test results, the value for the instrumental subscale was significantly higher than all the others, valence and integrative mean scores differed significantly from the effort, expectancy, and ability, and the last two were significantly higher than effort.

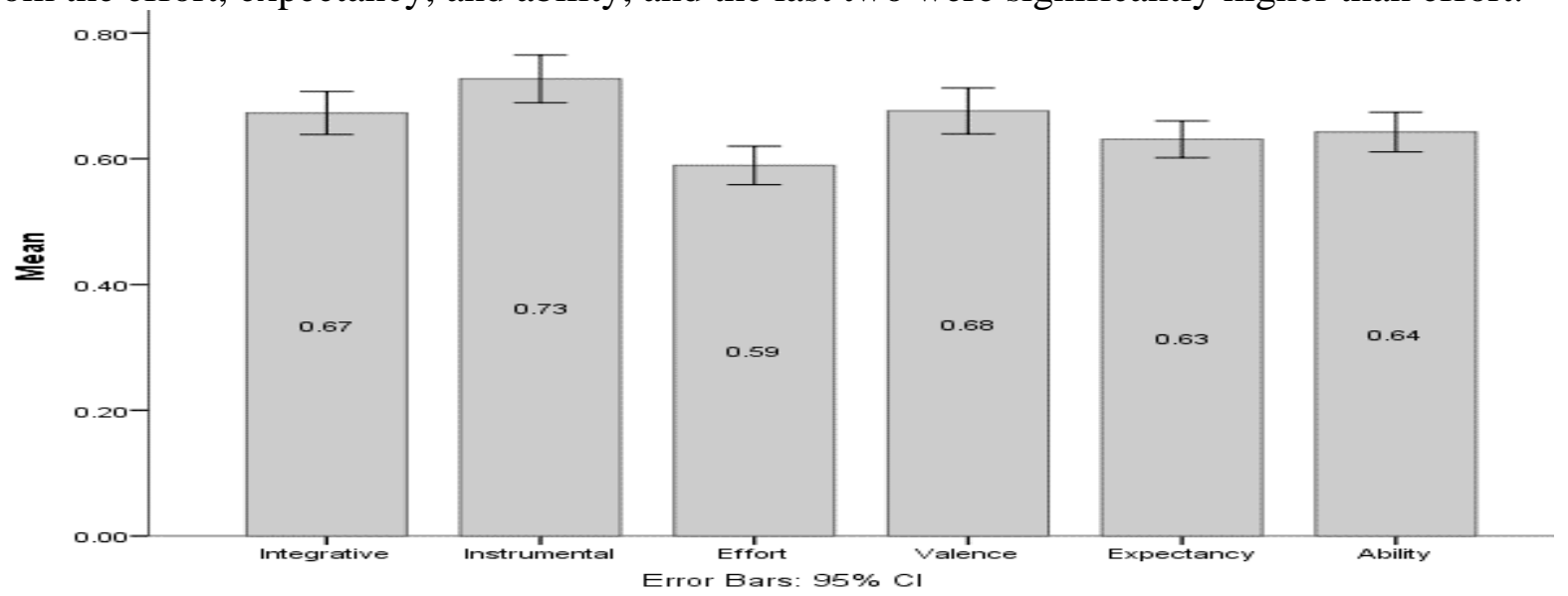

Figure 1. Mean values for normalized motivation subscales with $95 \%$ confidence intervals.

The correlation analysis performed for motivational subscales and the total score scale (Table 4) revealed that all the subscales are significantly $(\mathrm{p}<.01)$ moderately positively correlated to each other $(r=.427$ to .742$)$. Thus, the results prove that using MANOVA for overall motivation comparison between students with different English levels is appropriate. The highest correlations were between Integrative, Instrumental, and Valence subscales (all $r>0.6$ ) and between expectancy and ability subscales $(r=.742)$. 
The relationship of separate subscales to the total motivation score were overall similar (with $\mathrm{r}=.708$ to $\mathrm{r}=.841$, all $\mathrm{p}<0.01$ ). Valence and Integrative subscale were strongly correlated to total score than effort, which showed the lowest correlation among all the subscales.

Table 4

Motivation subscales intercorrelations

\begin{tabular}{|c|c|c|c|c|c|c|}
\hline & 1 & 2 & 3 & 4 & 5 & 6 \\
\hline \multicolumn{7}{|l|}{ 1. Integrative } \\
\hline 2. Instrumental & $.653^{* *}$ & & & & & \\
\hline 3. Effort & $.499 * *$ & $.463 * *$ & & & & \\
\hline 4. Valence & $.656^{* *}$ & $.690 * *$ & $.474 * *$ & & & \\
\hline 5. Expectancy & $.527 * *$ & $.507 * *$ & $.503 * *$ & $.600 * *$ & & \\
\hline 6. Ability & $.530 * *$ & $.427 * *$ & $.497 * *$ & $.528 * *$ & $.742 * *$ & \\
\hline 7. Total & $.819 * *$ & $.804 * *$ & $.708 * *$ & $.841 * *$ & $.802 * *$ & $.769 * *$ \\
\hline
\end{tabular}

Note: $* \mathrm{p}<.05, * * \mathrm{p}<.01$

Based on the participants' demographic information only independent variable that could be used for MANOVA was the level of English, as all the others did not provide big enough group sizes to run an analysis for six dependent variables.

Before running MANOVA, the dependent variables, motivation subscales' scores, were checked to fit the test's assumptions. Next, the univariate outliers were tested by constructing a boxplot for each variable within each group of English language levels. The boxplots were inspected for values greater than 1.5 box length from the edge of the box. There were only six outliers detected. All of them were checked for misprints and then included in the analysis as none of the outliers exceeded the 1.5 interquartile distance. There were no multivariate outliers in the data, as the highest value of Mahalanobis distance was lower than the critical value for six dependent variables $(\mathrm{p}<0.001)$.

The normality of the distribution of the dependent variables within each level of independent variables was assessed by the Shapiro-Wilk test (Table 5). It revealed that most distributions were normal except the fourth level English group, where Integrative, Instrumental, Effort, and Valence subscales did not match the normal distribution. Nevertheless, according to (Hair et al., 2006), the MANOVA procedure is relatively robust to violate the normality assumption if the sample size is big enough. Therefore, when running MANOVA on a nonnormally distributed date, special attention should be paid to Box's M test, which can be affected.

Table 5

Normality tests for motivation subscales by level of English

\begin{tabular}{lllllllll}
\hline \multirow{2}{*}{ Subscale name } & $\begin{array}{l}\text { Level 1 } \\
(\mathrm{df}=28)\end{array}$ & $\begin{array}{l}\text { Level 2 } \\
(\mathrm{df}=11)\end{array}$ & $\begin{array}{l}\text { Level 3 } \\
(\mathrm{df}=25)\end{array}$ & $\begin{array}{l}\text { Level 4 } \\
(\mathrm{df}=71)\end{array}$ \\
\cline { 2 - 10 } & Statistic & $\mathrm{p}$-value & Statistic & $\mathrm{p}$-value & Statistic & $\mathrm{p}$-value & Statistic & $\mathrm{p}$-value \\
\hline 1. Integrative & 0.954 & .245 & 0.926 & .375 & 0.973 & .729 & 0.942 & .003 \\
2. Instrumental & 0.911 & .021 & 0.930 & .409 & 0.839 & .001 & 0.866 & .000 \\
\hline
\end{tabular}


Arab World English Journal (AWEJ) Volume 12. Number 3. September 2021

Students' Motivation to Learn English as a Foreign Language

Aljuaid

\begin{tabular}{lllllllll}
\hline 3. Effort & 0.931 & .064 & 0.889 & .136 & 0.976 & .797 & 0.964 & .037 \\
4. Valence & 0.988 & .980 & 0.860 & .057 & 0.918 & .046 & 0.899 & .000 \\
5. Expectancy & 0.990 & .995 & 0.949 & .627 & 0.956 & .346 & 0.980 & .300 \\
6. Ability & 0.960 & .341 & 0.926 & .376 & 0.937 & .124 & 0.969 & .071 \\
\hline
\end{tabular}

Note: p-values $<0.05$ are marked italic

Levene's test for homogeneity of variance showed equal variance among all dependent variables (all $\mathrm{p}>0.1$ ). There was also a homogeneity of variance-covariances matrices as proved by Box's equality test of covariance matrices $(p=.449)$.

As the dependent variables fit most of the assumptions of MANOVA, the test was performed, and the results can be interpreted without danger of increasing Type 1 error.

\section{MANOVA results}

According to MANOVA, there were no significant differences in students' motivation to learn the English language between four groups of students according to their English knowledge level (Wilk's $\lambda=0.827, \mathrm{~F}(18,357)=1.379, \mathrm{p}=.139)$.

Furthermore, the univariate analysis performed for each of the subscales (Table 6) showed results well corresponding to multivariate analysis with only ability being statistically significantly different between four levels of English knowledge $(\mathrm{F}(3,131)=2.730, p=.047)$. Nevertheless, the p-value of the test was on the border of being insignificant, so these results should be treated with particular caution, especially taking into account that the assumption of the MANOVA was not fully satisfied.

Table 6

Univariate ANOVA for motivation subscales by the level of English

\begin{tabular}{lllll}
\hline & $F$ & $d f$ & Error $d f$ & $p$-value \\
\hline 1. Integrative & 2.297 & 3 & 131 & .081 \\
2. Instrumental & 0.429 & 3 & 131 & .732 \\
3. Effort & 1.833 & 3 & 131 & .144 \\
4. Valence & 1.640 & 3 & 131 & .183 \\
5. Expectancy & 0.734 & 3 & 131 & .533 \\
6. Ability & 2.730 & 3 & 131 & .047 \\
\hline
\end{tabular}

One limitation of the current research was the relatively small number of students with the first, third, and especially second level of English knowledge. Small sample size can affect the multivariate analysis of variance and lead to an increased probability of type 2 error, i.e., the difference that could be diagnosed as statistically significant, resulting in insignificance due to low sample size. The participants were grouped into two groups with English levels lower than four and English levels equal to four to check whether the low sample size for the level 2 group of students $(\mathrm{n}=11)$ has affected the analysis results. The size of the received groups was large enough and similar ( $n=64,47.1 \%$ for merged group of level 1 through 3 and $n=72,52.9 \%$ for the level 4 group) as most of the assumptions were tested before only normality and homogeneity of variance and variance-covariance matrixes needed to be checked within new groups. The normality tests for the level 4 group remained the same as in table 5, and for the merged level 1-3 group, the distribution of the Instrumental subscale violated the assumption ( $\mathrm{p}$ 
$<0.01)$. Levene's test of homogeneity of variance and Box's test of homogeneity of variancecovariance matrixes showed insignificant $(p>.05)$ results. Therefore, there is proof that the assumption of equal variance is met. Thus, the MANOVA can be used for the grouped level of English knowledge too.

The analysis results showed a significant difference in students' motivation of the first three levels compared to level 4 (Wilk's $\lambda=0.881, \mathrm{~F}(6,128)=2.873, \mathrm{p}=.012$ ). The effect size is measured by $\eta^{2}$, which indicates the proportion of dependent variable variation accounted for by an effect of the independent variable when all factors are fixed. According to Ferguson (2009) the proposed effect size borderlines suggestions for $\eta^{2}$ are: $\eta^{2}=.04$ is a recommended minimum for social sciences, $\eta^{2}=.25$ indicates moderate effect and $\eta^{2}=.64$ accounts for a strong effect. The current MANOVA had $\eta^{2}=.119$, which is higher than the minimum but still low to gain a moderate effect.

A follow-up univariate analysis compared the mean scores of separate motivation subscales between two groups of students. It showed that Integrative motivation and Effort, Valence, and Ability differ significantly between students of the first three levels of English knowledge compared to their counterparts who have reached the highest (fourth) level (Table 7). However, the motivation level of the students in the fourth level in English is significantly higher in terms of their intention to use English knowledge to integrate into the English-speaking world, their valence to receive better understanding, their readiness to provide more effort in studying, and their estimation of the ability to master English language.

Table 7

Univariate ANOVA for motivation subscales by the level of English

\begin{tabular}{lllllllll}
\hline & \multicolumn{2}{l}{ Levels 1-3 } & Level 4 & \multirow{2}{*}{ Error } & \multirow{2}{*}{-value } \\
& $M$ & $S D$ & $M$ & $S D$ & & $d f$ & $d f$ & \\
\hline 1. Integrative & 4.84 & 1.29 & 5.35 & 1.26 & 5.784 & 1 & 133 & .018 \\
2. Instrumental & 5.35 & 1.49 & 5.38 & 1.50 & 0.047 & 1 & 133 & .829 \\
3. Effort & 2.69 & 0.59 & 2.89 & 0.55 & 5.297 & 1 & 133 & .023 \\
4. Valence & 4.82 & 1.31 & 5.29 & 1.49 & 4.116 & 1 & 133 & .044 \\
5. Expectancy & 61.30 & 17.67 & 65.67 & 18.31 & 1.986 & 1 & 133 & .161 \\
6. Ability & 60.26 & 20.31 & 69.46 & 18.20 & 7.714 & 1 & 133 & .006 \\
\hline
\end{tabular}

\section{Discussion}

The main purpose of this study was to investigate the interrelatedness of motivation factors to learn English as a foreign language and the difference between students belonging to various socio-demographic groups. The analysis was performed among English as first foreign language students of different levels studying English and English literature as their major at the university. The main variables initially thought to be compared gender, age, and English as first language proficiency. However, while collecting the data, it revealed that most of the participants were female; all of them mentioned Arabic as their native language and had English as their first foreign language. Therefore, English proficiency level was the only characteristic available for comparative analysis. 
The overall level of students' motivation was relatively high; the mean value of the overall composite motivation score calculated based on normalized values for the motivation subscale was higher than average $(M=3.94$ on a scale from 0 to 6$)$. The instrumental motivation was the highest among the students, followed by integrative motivation and valence.

The interrelatedness of six motivation subscales (integrative motivation, instrumental motivation, effort, valence, expectancy, and ability) was estimated. Meanwhile, correlation analysis showed that all motivation subscales are significantly related. Furthermore, their relatedness to overall motivation is similar (Pearson's $\mathrm{r}$ varied from a minimum of 0.708 for effort subscale to a maximum of 0.841 for valence). These results state that all motivation factors play a significant role in overall students' motivation to learn English. Therefore, all of them should be taken into account when working with students in the class.

These results of correlation analysis do not fully correspond to previous research (Shaaban \& Ghaith, 2000), where only student's expectancy to achieve goals in learning English and their estimation of personal ability to reach these goals occurred to be highly ( $\mathrm{r}>0.9$ ) correlated to overall motivation. The main reason for this difference is in the way of calculating the overall motivation scale. The current study calculated the scores based on the sum of normalized scores for six subscales. In contrast, Shaaban \& Ghaith (2000) summarized the raw scores, and thus the 100-point scale used to measure participants' expectancy and ability showed the highest correlation with overall motivation score.

All motivation subscales appeared to be significantly interrelated, but some showed a higher value of correlation coefficient. So instrumental, integrative motivation, and valence appeared to be a group of three highly $(\mathrm{r}>0.65)$ interrelated motivation factors. This result corresponds to the work of (Belmechri \& Hummel, 1998; Dörnyei, 1990), stating that integrative and instrumental motivation can overlap in some zones. For example, when students learn EFL to further integrate into a professional community or are motivated by their desire to travel, their motivation can be treated both as Integration and Instrumental. Learning English is a necessary instrument to communicate with people worldwide. As Kormos and Csizér (2008) mentioned, when analyzing instrumental and integrative motivation, one needs to consider the unique position of the English language compared to all other languages as being a global one (Crystal, 2003). Thus, knowledge of English has been separated from the cultures and countries where it is a native language. The valence subscale measuring the personal importance of instrumental and integrative motives confirms the previous discussion is highly correlated to both subscales and indirectly having a high internal consistency value. Thus, this indicates that the scale items can be merged and used to measure one whole motivation factor. The next pair of highly related subscales were expectancy and ability $(r=0.742)$. This result follows previous research of Shaaban \& Ghaith (2000) and states the consistency of participants' motivation in terms of correspondence of their expectations to their current level of English proficiency.

The following research question was to compare the motivation between students of different English language levels. Due to the relatively low sample size of third-level students, the MANOVA analysis was performed twice for the 4-point variable of English language level and a grouped one consisting of two groups: levels below fourth vs. the fourth-level. The difference in students' motivation between four levels of English language proficiency was 
insignificant; however, when using a grouped variable of English level, there was a statistically significant difference in the motivation of students who already reached the fourth level of English and not. Furthermore, these results were similar to previous research (Shaaban \& Ghaith, 2000; Vijchulata \& Lee, 1985) in terms of indicating there was a difference in students' motivation. Furthermore, the motivation subscales that significantly differed as assessed by univariate analysis were similar to the results of Shaaban \& Ghaith (2000): Integrative motivation, effort, and valence were revealed as statistically significantly different between students of two EFL levels, and ability was significantly different estimated in current research. The usage of the grouped variable can cause the last finding to measure EFL proficiency, where the first group of students consisted of three levels from 1 to 3. Therefore, there were students whose level of English differed much from the second group of $4^{\text {th }}$ level students. Remarkably, the sign of motivation difference did not match the one mentioned in Shaaban \& Ghaith's (2000) research. In contrast, it complied with other research results (Janati \& Marzban, 2014; Lee \& Oh, 2011; Vijchulata \& Lee, 1985) and stated, the motivation was higher among students with a higher level of English proficiency.

One of the limitations of the current study was the unequal sample size of different levels of English proficiency and especially a low number of third-level students. This was one of the main reasons to conduct analysis based on merged 1-3 level group, which did not allow investigating the specific difference between these students.

\section{Conclusion}

Based on the results of the study, it can be concluded that the motivation measured by modified Wen (1997) instrument consisting of six motivation subscales provides a good evaluation of student's motivation in learning English as a foreign language presents the ability to analyze overall motivation level and significant aspects simultaneously.

Students' valence, along with instrumental and integrative motivation proved to be the main contributors to an overall increase in motivation, which corresponds to previous research in motivation to learn a foreign language. Therefore, when working on the programs dedicated to increasing students' overall motivation and orientation to learn English, English teachers can use these results and provide corresponding focus to their programs.

The difference in motivation level between students of different English proficiency levels could be investigated in further research, overcoming the main limitation of the current survey - the low sample size for some group levels.

\section{Declaration of conflicting interests}

The author has no conflicts of interest to declare.

\section{About the author}

Dr. Hind Aljuaid is currently an assistant professor of Applied Linguistics in the Foreign Languages Department at Taif University, Saudi Arabia. Aljuaid has obtained her PhD from Griffith University, Australia in 2015, an MA in Applied linguistics from Griffith University, Australia in 2010. Dr. Aljuaid research interests include language learning strategies, the studies 
of English language learners, and English language learning and teaching in an EFL context. ORCID: https://orcid.org/0000-0001-6528-1235

\section{References}

Anjomshoa, L., \& Sadighi, F. (2015). The importance of motivation in second language acquisition. International Journal on Studies in English Language and Literature (IJSELL), 3(2), 126-137.

$\mathrm{Au}, \mathrm{S}$. Y. (1988). A critical appraisal of Gardner's social-psychological theory of secondlanguage (L2) learning. Language learning, 38(1), 75-99.

Batubara, F., Derin, T., Putri, N. S., \& Yudar, R. S. (2020). Five Factors Influencing the Students' Motivation to Learn English as a Foreign Language: A Closer Look into Montessori Classroom Environment. REiLA: Journal of Research and Innovation in Language, 2(2), 76-84.

Belmechri, F., \& Hummel, K. (1998). Orientations and motivation in the acquisition of English as a second language among high school students in Quebec City. Language learning, 48(2), 219-244.

Claro, J. (2016). Japanese first-year engineering students' motivation to learn English. Studies of Human Science, 12, 67-105.

Crystal, D. (2003). English as a global language: Ernst Klett Sprachen.

Dörnyei, Z. (1990). Conceptualizing motivation in foreign-language learning. Language learning, 40(1), 45-78.

Ferguson, C.F. (2009). An effect size primer: a guide for clinicians and researchers. Professional

Psychology: Research and Practice 40(5): 532-538.

Gardner, R. C., \& Lambert, W. E. (1959). Motivational variables in second-language acquisition. Canadian Journal of Psychology/Revue canadienne de psychologie, 13(4), 266.

Hair, J. F., Black, W. C., Babin, B. J., Anderson, R. E., \& Tatham, R. (2006). Multivariate data analysis. Uppersaddle River: NJ: Pearson Prentice Hall.

Janati, M., \& Marzban, A. (2014). The Relationship between Iranian EFL learners' motivation and their English proficiency level. Journal of Studies in Learning and Teaching English, 2(6), 65-79.

Jin, M. (2014). A case study of non-English major college students' motivation in English language learning. Open journal of modern linguistics, 4(02), 252.

Kormos, J., \& Csizér, K. (2008). Age-related differences in the motivation of learning English as a foreign language: Attitudes, selves, and motivated learning behavior. Language learning, 58(2), 327-355.

Lee, E.-H., \& Oh, H. J. (2011). Relationship between motivation and proficiency improvement. Linguistic Research, 28(2), 405-430.

Nawaz, H., Amin, M., \& Tatla, I. A. (2015). Factors Affecting Students' Motivation Level to Learn English as a Second Language in the Pakistani University Context. Journal of Research \& Reflections in Education (JRRE), 9(2).

Ngo, H., Spooner-Lane, R., \& Mergler, A. (2017). A comparison of motivation to learn English between English major and non-English major students in a Vietnamese university. Innovation in Language Learning and Teaching, 11(2), 188-202. 
Oller Jr, J. W. (1981). Can affect be measured? International Review of Applied Linguistics, 19(3), 227-235.

Pham, C. (2016). Identifying socio-cultural influences on high school students' motivation to learn English in rural areas in Vietnam. New Zealand Studies in Applied Linguistics, 22(1), 5-20.

Rahman, H. A., Rajab, A., Wahab, S. R. A., Nor, F. M., Zakaria, W. Z. W., \& Badli, M. A. (2017). Factors affecting motivation in language learning. International Journal of Information and Education Technology, 7(7), 543-547.

Shaaban, K. A., \& Ghaith, G. (2000). Student motivation to learn English as a foreign language. Foreign language annals, 33(6), 632-644.

Suryasa, W., Prayoga, I., \& Werdistira, I. (2017). An analysis of students' motivation toward English learning as a second language among students in Pritchard English academy (PEACE). International journal of social sciences and humanities, 1(2), 43-50.

Vibulphol, J. (2016). Students' Motivation and Learning and Teachers' Motivational Strategies in English Classrooms in Thailand. English Language Teaching, 9(4), 64-75.

Vijchulata, B., \& Lee, G. S. (1985). A survey of students' motivation for learning English. RELC Journal, 16(1), 68-81.

Wen, X. (1997). Motivation and language learning with students of Chinese 1. Foreign language annals, 30(2), 235-251. 